\title{
REVISTAMARACANAN
}

Dossiê

\section{A construção do homem americano no século XVIII: viagens, teorias e o inventário da humanidade do Novo Mundo ${ }^{1}$}

\author{
Making the American man in the Eighteenth century: travel, theories and \\ inventory of the New World humanity
}

\author{
Bruno Silva \\ Universidade Federal Fluminense \\ slvbruno2004@yahoo.com.br
}

\begin{abstract}
Resumo: O presente artigo analisa relatos de viagens ultramarinas implementadas durante o século XVIII, associando-os com as teorias desenvolvidas pelos filósofos naturais europeus em centros de pesquisas na Europa para, dessa forma, checar como a reescrita da história da América no Século das Luzes foi fundamental para a classificação da humanidade presente no Novo Mundo e, por conseguinte lançar mão de argumentos que fugiam do campo do maravilhoso, atuando assim, no desenvolvimento da ideia de raça com base nos aspectos físicos e também na possível percepção dos súditos dos grandes monarcas imperiais de que eles eram considerados diferentes frente à ideia europeia de raça ideal.
\end{abstract}

Palavras-chave: Viagens ultramarinas; Século XVIII; Homem americano.

Abstract: This article seeks to analyze overseas travel reports implemented during the eighteenth century, as well as the theories developed by European natural philosophers in research centers in Europe and thus observe how to rewrite the history of America in the Age of Enlightenment was fundamental for humanity classification in the New World and, consequently, to the development of the race idea considering the physical aspects and the perception of the subjects of the great imperial monarchs who were considered different across the European perception of ideal race.

Keywords: Overseas travel; Eighteenth century; American native.

Artigo recebido para publicação em: Março de 2016

Artigo aprovado para publicação em: Maio de 2016

1 Pesquisa financiada pela Capes, no Brasil, e em arquivos e bibliotecas da Universidade do Texas, nos Estados Unidos. 
o Século das Luzes, sob o manto da pesquisa científica, os estudiosos da velha Europa inventariaram ${ }^{2}$ as riquezas naturais e a humanidade que se encontravam no Novo Mundo, apresentando novos relatos a respeito da América. Partindo da premissa de que aquela parte da Terra fora mal explorada e desconhecida em detalhes por conta da incapacidade que os homens dos séculos XVI e XVII tiveram de confeccionar relatos verdadeiros e com aparato científico a respeito da América, os teóricos de gabinetes, associados, quase sempre, a algum organismo de pesquisa como as academias de ciências ${ }^{3}$ ou os monarcas, à frente dos grandes impérios coloniais europeus, com auxílio de viajantes escolhidos para (re)conhecerem as mais distantes paragens americanas, resolveram reescrever a história do Novo Mundo, para explorar de forma mais racional a flora e fauna desses espaços e, não menos importante, classificar a diversidade humana encontrada nos domínios imperiais na América. ${ }^{4}$

Assim, as viagens filosóficas como as implementadas pelos monarcas europeus, bem como as expedições de particulares que fabricaram relatos a respeito do Novo Mundo, foram primordiais para estreitar os laços entre os centros imperais e seus domínios na América, a fim de garantir maior controle desses espaços em favor do desenvolvimento econômico dos impérios. Espanha, Portugal e França organizaram diferentes expedições à América com o intuito de melhor explorar as riquezas do Novo Mundo e, ao mesmo tempo, manter o governo a distância e a lealdade dos súditos espalhados por aquelas regiões. ${ }^{5}$

Mas, as novas disputas a respeito da origem da humanidade encontrada na América, a razão da coloração de suas peles, a forma como agiam culturalmente, religiosamente e como funcionavam suas estruturas políticas, econômicas e mentais, decerto, apontou para diferentes hipóteses que, inevitavelmente, se chocavam. Os inventários que tentavam dar conta do homem do Novo Mundo acabavam por levar os letrados da terra a escreverem suas próprias opiniões a respeito de suas origens, num embate entre o conhecimento científico que se

\footnotetext{
${ }^{2}$ A expressão "inventariar" me parece adequada para nomear o processo de catalogação e novos relatos feitos sobre a flora, a fauna e o homem do Novo Mundo, especialmente após a segunda metade do século XVIII, compartilhando, dessa forma, a tese do historiador Ronald Raminelli que enfatiza: "no século XVIII, os sábios do Velho Mundo planejavam realizar um grande inventário da natureza e dos povos, para tanto, percorreram os mares e as terras com equipes de jardineiros e artistas [...]". Ver: RAMINELLI, Ronald. Viagens Ultramarinas: monarcas, vassalos e governo a distância. São Paulo: Alameda, 2008. p. 98.

${ }^{3}$ Instituições como Jardin des Plantes, em Paris, Real Museu Natural e Jardim Botânico da Ajuda, em Portugal, Museu da História Natural e Academia de Ciências de Lisboa e Academia de Ciências de Berlim são exemplos de organismos de pesquisa que marcaram a produção de pensamento científico ao longo do século XVIII.

${ }^{4}$ Sobre esse assunto, ver: CAÑIZARES-ESGUERRA, Jorge. Como escrever a História do Novo Mundo: Histórias, Epistemologias e Identidades no Mundo Atlântico do século XVIII. São Paulo: Edusp, 2011. A ideia de reescrita da história da América é muito bem estruturada na obra de Cañizares-Esguerra e, portanto, aqui compartilhada. Para o autor: "durante o século XVIII ocorreram debates de longo alcance sobre como escrever a história do Novo Mundo e seus povos. [...] Quando novas técnicas críticas para criar e validar o conhecimento amadureceram na Europa, alguns estudiosos começaram a questionar a autoridade e a confiabilidade das fontes que os historiadores e cronistas tradicionalmente usavam". Portanto, houve uma releitura e uma reescrita da história da América e dos seus povos.

${ }^{5}$ Cf. RAMINELLI, Ronald. Viagens Ultramarinas: monarcas, vassalos e governo a distância. São Paulo: Alameda, 2008.
} 
desenrolava na Europa e aquele que se desenvolvia na América, construindo assim, no século XVIII, a ideia de um homem americano.

Qualquer artista que fosse convidado a representar em imagens algum relato sobre a natureza e a humanidade da América, na segunda metade do século XVIII, de alguma forma, poderia se surpreender com as descrições colocadas à sua frente. Afinal, seria preciso exteriorizar uma parte do mundo em que a região do Panamá seria afligida por serpentes venenosas; Cartagena das Índias, por nuvens de enormes morcegos; Portobelo, por estranhos sapos; Suriname, por baratas albinas; Guadalupe e outras colônias seriam tomadas por besouros roedores; Quito, por pulgas; Lima, por piolhos e cupim; e o Brasil, por muitas formigas. ${ }^{6}$ Visão de um mundo: o mais desconhecido da humanidade; não obstante, o mais cruelmente assolado pelo devastador poder do clima que não só ofereceu ao europeu a possibilidade de contato com uma natureza degenerada, mas também com um homem que se desenvolveu sob os auspícios de um ambiente adverso à vida civilizada.

E essa vaga de estranhos animais acima mencionados desfilava nas páginas da obra de Cornelius de Pauw que, apesar de não ter conhecido a América pessoalmente, desafiou ao escrever suas Recherches philosophiques e se surpreendeu do quanto os americanos formavam o capítulo mais curioso e o menos conhecido da História do homem, destacando que sua proposta era fazer com que o ser humano do Novo Mundo se tornasse o principal objeto de sua extensa pesquisa. Assim, ele propunha entender a constituição física e, por vezes, a singularidade das ideias morais dos indígenas. Para ele, não havia evento mais memorável entre os homens do que a descoberta da América e se os seus contemporâneos se remontassem do tempo deles ao mais recuado, não haveria nenhum acontecimento que se pudesse comparar àquele; sendo, sem dúvida, um espetáculo grande e terrível de ver, uma parte do globo, tão desgraçada pela natureza, em que tudo se degenerava ou era monstruoso.

William Robertson também defendia que, no mundo americano, o estado da humanidade era rude e os aspectos da natureza extremamente diferentes. Nas regiões mais ao sul onde o calor do sol, a umidade do clima e fertilidade do solo combinavam invocando os poderes mais rigorosos da vegetação, as florestas ficavam sufocadas, quase impermeáveis, tornando a superfície do solo escondida e sob o domínio de uma espessa camada de arbustos e ervas daninhas. Nesse estado de natureza selvagem, sem melhoras, uma grande parte das províncias da América do Sul permaneciam estendidas desde a base dos Andes até o mar. As colônias europeias tentavam limpar e cultivar alguns pontos ao longo da Costa, mas a raça original de habitantes, rudes e indolentes como sempre, não fazia absolutamente nada para melhorar a região. ${ }^{7}$

De Pauw e William Robertson eram herdeiros do pensamento filosófico que se desenvolveu a partir da segunda metade do século XVII - tendo sua expressão maior após os

\footnotetext{
6 PAUW, Cornelius de. Recherches philosophiques sur les américains ou Mémoires intéressants pour servir à I'historire de l'espèce humaine. Tome 1. Berlim: Chez George Jacques Decker, Impr. Du Roi, $1768 . p .8$. 7 ROBERTSON, William. The history of America. London: Printed for A. Strahan; T. Cadell, in the Strand; and J. Balfour, at Edimburgh, 1792, livro 4.
} 
anos 1750 -, no qual as classificações que pareciam dar conta da divisão da humanidade, como as que a dividiam em dois grupos (civilizados ou selvagens e cristãos ou pagãos), aos poucos, foram perdendo espaço e rivalizando com outras que buscavam, através da ciência natural, mudar as perspectivas classificatórias. O advento da medicina, da ciência natural e da ciência política levou o ser humano a se tornar objeto de estudo. Aos naturalistas coube a missão de estabelecer sistemas naturais que dessem conta da diversidade humana, procurando, assim, formas de classificação para os diferentes tipos humanos existentes na Terra. E, quase sempre, essas posições poderiam ser ambíguas, como bem afirmou o historiador Antonello Gerbi, ao analisar a posição de De Pauw a respeito da natureza americana. ${ }^{8}$

As obras dos teóricos da segunda metade do século XVIII, quase sempre, dialogavam com as publicações daquele que seria entronizado pela historiografia como o grande nome da história natural, no Século das "Luzes": conde de Buffon. Em suas pesquisas, abordava um discurso sobre a natureza do homem e apontava para uma parte anatômica, considerando o homem em diferentes estágios da vida - infância, puberdade, idade viril, velhice e morte; e a parte que mais se aproximava do que aqui apresentamos, ou seja, as variedades da espécie humana. Michelle Duchet lembra que, para Buffon, os animais nunca haviam inventado ou aperfeiçoado nada, diferentemente dos homens, cuja característica transformadora se estendia a toda espécie humana, sendo a reflexão, a linguagem e a perfectibilidade as marcas indeléveis dos grupos humanos. ${ }^{9}$ Assim, a obra de Buffon se baseava na diferença entre o homem e os animais, na qual o primeiro, em qualquer circunstância, era superior. E a base de Buffon era a defesa da unicidade das espécies, uma vez que acreditava, não por motivos meramente religiosos, numa única matriz criacional da humanidade.

Tzvetan Todorov, por seu turno, acredita que Buffon criou uma matriz classificatória baseada em dois pontos importantes quando buscava apreender as diferenças entre homens e animais. Além da razão, a capacidade de reconhecimento hierárquico também era responsável por conceder ao ser humano um lugar de superioridade. Assim, o filósofo natural, ao compreender que não se podia ver entre os animais um servindo o outro, um sendo comandado pelo outro ou se sentindo superior aos demais, entendia existir aí um grau de inferioridade. ${ }^{10}$

\footnotetext{
8 GERBI, Antonello. O Novo Mundo: história de uma polêmica (1750-1900). São Paulo: Cia. das Letras, 1996, p. 61 destaca que: "às vezes do clima, ou seja, de fatores naturais constantes, mas com prudente reserva, e com muito maior frequência recorre às catástrofes, a inundações e outros flagelos insólitos. A hipótese de um dilúvio parece-lhe explicar "a maior parte das causas que na [na América] viciaram e depravaram o temperamento dos habitantes", melhor que "a hipótese de mr. Buffon, o qual supõe que a natureza, ainda adolescente na América, mal acaba de organizar e dar vida aos seres. Por outro lado, acena obscuramente com 'catástrofes físicas', com 'medonhos tremores de terra', 'inundações consideráveis', com 'combustão generalizada e de assombrosas vicissitudes', que constituem 'as maiores dificuldades e, ao mesmo tempo, os pontos mais interessantes da física do globo e da história dos seres". ${ }^{9}$ DUCHET, Michèlle. Buffon. De I'homme. Paris: F. Maspero, 1971.

10 TODOROV, Tzvetan. Nós e os outros: a reflexão francesa sobre a diversidade humana. I. Rio de Janeiro: Zahar, 1993. p. 115.
} 
Em relação ao homem americano e sua posição no quadro classificatório de Buffon, Robert E. Bieder destaca que o filósofo percebia as Américas literalmente como um novo mundo dentro de uma escala geológica e, portanto, a Terra teria emergido recentemente do mar, estando ainda coberta de lagos, pântanos e selvas que produziam um ar úmido e tóxico. E, para o autor, assim como Buffon, tantos outros compartilhavam da tese segundo a qual os indígenas eram "children of nature mirrored a certain innocence, but basically their physiques and cultures were the products of degeneration caused by an adverse environment". ${ }^{11}$

Partindo desses parâmetros, ao analisar algumas características de povos americanos, Buffon concluía que muitas dessas gentes viviam como se tivessem degenerado da espécie humana. E toda a sua feiura, bizarria e deformações levavam a crer que era uma variedade inferior, física e moralmente, e que "vivant à l'écart, à la limite du monde habité, ils forment une humanité presque marginale, que la rigueur du climat voue à la 'dégénération' dans les espaces où ils se sont aventurés". ${ }^{12}$ Mas, apesar da importância da obra de Buffon em promover uma síntese das teses que abordavam as diferenças humanas, não se pode perder de vista que há um certo peso concedido pelos pesquisadores à sua obra que deve ser matizado. A despeito da posição inovadora de Buffon e daqueles que caminharam pelo mesmo rumo em apontar a degeneração da natureza americana, tal posição não pode ser aplicada ao fato da degenerescência do nativo americano, hipótese destacada, reiteradamente, antes das teorias do Conde.

Em 1719, em obra denominada Réflexions critiques sur la poésie et sur la peinture, o autor Jean-Baptiste Dubos, homem de influência no governo francês e membro da Academia Francesa, destacava que o ambiente era o responsável direto pelas qualidades que os seres humanos possuíam. Assim, o ar seria o principal elemento causador das diferenças nos seres, os efeitos do ar eram levados via respiração até o sangue e, portanto, impregnava o indivíduo com qualidades inerentes àquele ambiente onde ele vivia. Assim, o ambiente europeu era mais saudável e mais propício a produzir corpos sadios e cérebros mais aptos a desenvolver a arte. Quanto à América e sua humanidade, o autor destacava a preocupação que o governo espanhol possuía ao ter que lidar com os nativos do Novo Mundo, mesmo aqueles que eram filhos de espanhóis nascidos na América, afinal eram todos oriundos de uma humanidade degenerada pelo ambiente. ${ }^{13}$ Por fim, Dubos explicava o quanto o ambiente onde os seres

\footnotetext{
${ }^{11}$ BIEDER, Robert E. Science encounters the Indian, 1820-1880: the early years of American ethnology. The University Of Oklahoma Press, 1986. p. 6-9.

12 DUCHET, Michèlle. Présentation et notes... In: BUFFON. De I'homme. Paris: Librairie François Maspero, 1971. p. 19.

13 DUBOS, Jean-Baptiste. Réflexions critiques sur la poésie et sur la peinture. Par J. B. Dubos, 1719. p. 260. Ao abordar o homem americano, o autor destaca que: "La Cour de Madrid qui fit toujours une attention serieuse sur le caractere $\&$ sur le genie particulier des diverses Nations qu'elle gouvernoit, [...]. Cette Cour circonspecte a toujours euë pour maxime de ne point confier en Amerique aucun emploi d'importance aux Espagnols Crioles ou nez en Amerique. Cependant ces Crioles sont les habitants qui sont nez d'une mere \& d'une pere Espagnols, sans aucun mélange de sang Americain ou Afriquain. Ceux qui sont nez d'un Espagnol \& d'une Americaine s'appelent Mestisses \& ils se nomment Mulatres quand la mere est Négresse. L'incapacité des sujets a eu autant de part à cette politique que la crainte qu'ils ne se soulevassent contre I'Espagne. Veritablement on a peine à concevoir à quel point le sang Espagnol, si brave \& si courageux en Europe, a dégeneré dans plusieurs contrées de l'Amerique. On ne le croiroit pas
} 
humanos se encontravam era responsável por influenciar em cada parte do corpo, interna e externamente, demonstrando assim, as características de cada raça. ${ }^{14}$

De fato, tais aspectos utilizados por Dubos para explicar as diferenças humanas e justificar a alocação do homem americano em posição inferior se comparado com o homem europeu também não são originais, pois a historiadora Lorelai Kury nos lembra que:

[...] ce genre d'appoche rejoint le modèle medical neo-hippocartique, très influent en Europe depuis le XVII siècle. Les conceptions humorales et climatiques d'Hippocarte ont toujours été présentes dans le médecine occidentale, mais, allies aux methods empiristes et à la philosophe sensualiste, elles connaissent un renouveau à partir de la deuxième moitié du XVIII siècle. ${ }^{15}$

Entretanto, no Século das Luzes, sob o manto da ciência, tais diferenças foram referendadas e acolhidas como teorias justificadoras da inferioridade do homem das Américas.

\section{O Novo Mundo e sua raça de homens desconhecidos: as hipóteses dos teóricos e viajantes do Século das "Luzes"}

Em relação à origem do homem americano, De Pauw era criterioso e dizia não acreditar na hipótese segundo a qual o homem do Novo Mundo teria mais de seiscentos anos. Sendo assim, ele entendia que o estabelecimento dessa barreira cronológica era um grande erro que se sucedeu e se manteve ao longo dos trabalhos sobre a origem dos nativos americanos. Mas se a vida selvagem, a falta de agricultura e de alfabeto podiam ser destacadas como marcas da recente origem de um povo, os lapões e os negros, decerto, seriam os mais atuais homens da Terra. Todavia, o teórico alertava para se ter cuidado com tal tese, uma vez que nenhum professor de cronologia teria, até então, conseguido estabelecer a antiguidade daqueles povos.

Mas, seja como for, De Pauw entendia que o homem americano, embora fosse bom corredor, leve e ágil, era destituído da força física resultante da tensão e da resistência dos músculos e nervos. O menos vigoroso dos europeus venceria uma luta com os americanos, o que demonstrava que a diferença entre os selvagens da América e os das regiões da Alemanha era de fato o poder dos membros fortes e dos corpos maciços e infatigáveis dos últimos. Os americanos se exauriam facilmente debaixo de qualquer carga, sobretudo quando estavam a

si douze ou quinze Relations differentes des expeditions des Flibustiers dans le nouveau monde, ne s'accordoient pas toutes à le dire \& à en rapporter des circonstances convaicantes".

14 DUBOS, Jean-Baptiste. Réflexions critiques sur la poésie et sur la peinture. Par J. B. Dubos, 1719. p. 242. Sobre o ambiente e os corpos, o autor apontava que "Or, si la diversité des climats peut mettre tant de varieté \& tant de difference dans le teint, dans la stature, dans le corsage des hommes \& même dans le son de le voix, elle doit mettre une difference encore plus grande entre le genie, les inclinations $\&$ les moeurs des nations. Les organnes du cerveau ou les parties du corps humain qui decident en parlant physiquement de l'esprit \& des inclinations des hommes, sont sans comparaison plus composées \& plus delicates que les os \& les autres parties qui décident de leur stature \& de leur force".

15 KURY, Lorelai. Histoire naturelle et voyages scientifiques (1780-1830). Paris: L'Harmattan, 2001. p. 195. 
trabalho para os espanhóis, que teriam perdido milhares de vidas indígenas por conta dos árduos afazeres aos quais submeteram os nativos.

William Robertson negava a possibilidade de que povos europeus teriam ocupado a América formando essas nações no novo continente, pois, nos seus dizeres, os nativos americanos encontrados pelos europeus estavam em estado de barbárie que já tinha sido vencida pelas nações mais avançadas, havia muito tempo. E, portanto, era impossível que o homem americano fosse de origem europeia, circunstância que o levou a acreditar que eram oriundos de tribos bem atrasadas em seu desenvolvimento. Acreditava ainda que os americanos poderiam ser originários dos tártaros. Contudo, todos possuíam a mesma ascendência, uma vez que, com menos ou mais características de semelhança, inclusive com variedades nos tons da pele, cada tribo possuía, num só tempo, algo de peculiar que a distinguia e caracteres comuns a todos daquela raça de americanos.

Robertson lembrava que, em um primeiro momento, o encontro com os habitantes do Novo Mundo encheu os descobridores de espanto, pois imaginaram que se tratava de uma raça de homens diferentes. A pele era como o marrom avermelhado, quase lembrando o cobre; o cabelo das cabeças, quase sempre longo, preto e liso. Não possuíam barbas e cada parte do corpo era perfeitamente lisa, de boas proporções, embora muitas vezes distorcidas para aparentar mais beleza ou para tornar seus aspectos mais terríveis aos olhos inimigos. Nas ilhas, no entanto, os seres humanos apresentavam formação débil. No limite, o rosto sem barba e a pele lisa do americano pareciam indicar um defeito em seu vigor, ocasionando vícios em seus quadros constitutivos. Assim, ele era destituído de forte sinal de virilidade e força e isso não poderia se atribuído à má alimentação com pouco uso do sal nas comidas, como diziam alguns viajantes. Outra característica destacada por Robertson era a falta de apetite sexual dos americanos, demonstrando total desinteresse pelas coisas do amor e da paixão; sendo essa, mais uma explicação para a degeneração da espécie. ${ }^{16}$

Jean Bernard Bossu, capitão francês em viagem pela América entre 1751 e 1770, afirmava que, ao questionar os índios chamados de Sioux, então povos vagantes, sobre sua origem, teriam dito que ouviram falar de outros indígenas da região Oeste do país, que navegavam em grandes lagos com grandes canoas e moravam em grandes aldeias construídas de pedras esbranquiçadas, vivendo sob o governo de um líder despótico possuidor de exércitos formidáveis. No fim, Bossu ficava em dúvida se realmente o homem americano teria vindo de outro continente, uma vez que, nesse caso, a raça de homens brancos seria perpetuada, pois, após dois séculos e meio em que Cristóvão Colombo havia colocado os pés no Novo Mundo, os europeus que nessas terras se instalaram conservaram, de uma geração a outra, a brancura de seus antepassados. Além disso, os animais encontrados na Europa eram completamente diferentes daqueles encontrados na América. ${ }^{17}$ Petrus Camper, professor e estudioso nascido

\footnotetext{
16 ROBERTSON, Op. cit., livro 4.

17 BOSSU, Jean Bernard. Nouveaux voyages dans L'Amérique Septentrionale: contenant une collection de lettres écrites surles lieux par l'auteur, à son ami M. Douin, Chavelier, Capitaine dans les Troupes du Roi,
} 
na Holanda, discordava da teoria do clima como responsável pelas diferenças entre os homens e, em obra publicada no ano de 1792, lembrava que as comunicações humanas foram responsáveis pelo aparecimento de diferentes raças. Assim, os americanos, ao que Ihe parecia, eram oriundos do Norte da Ásia, sobretudo quando se observava a semelhança entre os ângulos faciais desses dois povos; sem contar os usos, costumes e princípios religiosos que apresentavam.

Logo, Camper descartava as ideias religiosas que, interpretadas através da bíblia, justificavam a diversidade humana dispersa pelo globo terrestre. Entendia que qualquer pessoa sem preconceito, ao considerar a espécie humana como se encontrava espalhada pela Terra, duvidaria que tal humanidade teve sua origem em apenas um homem e uma mulher, discordando, portanto, de Buffon. Além disso, a consideração da tonalidade na classificação dos seres humanos não deveria ter papel principal, uma vez que a cor da cútis, ao longo dos tempos, poderia se deteriorar, muito embora os homens mantivessem a mesma textura da pele. Partindo desse pressuposto, Camper destacava que era irrelevante se a coloração original dos primeiros homens era preta ou branca. ${ }^{18}$

Mas, se os americanos não possuíam cabelos nem nas partes naturais e nem na pele o que os distinguia de todas as outras nações -, tal fato não demonstrava nada de anormal, segundo De Pauw, assim como o escroto de tamanho alterado em alguns homens e a pequenez do aparelho reprodutor também não resultavam em influências negativas. Outra característica que chamava a atenção era o inchaço do membro genital de alguns, o que não deveria, segundo o autor, ser considerado como algo natural, mas como efeito de arte, pois, com algumas atitudes, os indígenas faziam com que seus pênis tivessem aquela configuração monstruosa, num ato muito perigoso para se alcançar aquele objetivo.

Ao observar os órgãos genitais dos nativos, Jean-François de La Pérouse, na sua viagem pelo mundo - promovida pelo governo francês para reconhecimento dos diferentes povos da Terra e para melhor exploração de novas regiões em nome da Coroa de França -, afirmava não existir nenhuma comprovação de que algo estava errado com tais partes do corpo. E se considerasse a perfeição com que, aparente e externamente, se apresentavam aquelas partes, ele podia concluir que nada havia de estranho. Logo, escrevia que não vira em nenhuma das regiões por onde esteve, nem o prolongamento dos sacos escrotais, nem qualquer inchaço prodigioso nos pênis, assim como qualquer diferença substancial nos seios daquelas que ofereciam o leite, assumindo mesmo que se tratava de ilusões de viajantes ávidos por detratar a natureza americana. E com seu posicionamento, o viajante duvidava das teorias apresentadas por De Pauw e Buffon.

ci-devant son camarade dans le Nouveau-Monde. Nouvelle Édition. A Amsterdam et a Paris, chez la veune DUCHESNE, Libraire, Rue St-Jacques, au Temple du Goût, 1772.

18 CAMPER, Petrus. Dissertation sur les variétés naturelles qui caractérisent la physionomie des hommes des divers climats et des différens ages: suivie de réflexions sur la beauté, particulièrement sur celle de la tête... on y a joint une dissertation, du même auteur, sur la meilleure forme des souliers. Paris: Francart, 1792. p. 16. Sobre a origem dos povos: "Le peuple de chaque pays offre par conséquent quelque chose de particulier, qui se trasmet de génération en génération ce que, par le mélange de plusieurs nations, ce traits característiques se trouvent altérés ou entièrement détruits". 
Gilbert Imlay, capitão que serviu no exército americano durante a Revolução, considerava que os índios americanos não nasciam brancos e, ao longo da vida, existia um grande esforço por parte dos nativos no sentido de escurecer a pele, não só usando produtos que colocados na cútis os levavam a se exporem ao sol, mas também usando pinturas em seus rostos, seios e ombros, de várias cores, sobretudo o vermelho. E seus corpos eram proporcionalmente bem formados, sendo os das mulheres perfeitos. Não se admitia, entre aqueles povos, os pelos no corpo, por isso eram sempre retirados. Em muitas nações até o cabelo era raspado, de forma que ficava um pouco no alto da cabeça. ${ }^{19}$ Segundo Imlay, o clima americano era o responsável pela coloração avermelhada dos nativos, assim como o ambiente africano era culpado pela cor preta dos homens oriundos daquela região.

Conforme De Pauw, o sangue dos índios ocidentais, em sua época, já estava bem misturado com o dos europeus, negros e mulatos, formando seres híbridos de toda espécie. Por isso, alguns nativos nasciam com penugens na região da virilha, o que era totalmente descartado por eles, por vários motivos, dentre os quais, as questões religiosas. Para o autor, alguns povos fugitivos e errantes que mantiveram sua raça "sem a cruz", estavam, naquele momento, como se encontravam quando da descoberta do Novo Mundo, ou seja, absolutamente sem pelos em todo o corpo. E tal formato físico, longe de ser uma prova de força e valentia, segundo De Pauw, era uma demonstração de fraqueza, devido mais ao clima e temperamento dessas nações em geral do que às boas maneiras e à forma como se alimentava cada um desses grupos em particular.

Assustavam o teórico os relatos de viajantes de que, em algumas partes mais quentes da América, os homens nasciam com leite em suas mamas, sendo responsáveis, inclusive, pelo aleitamento das crianças, uma notícia estranha, mas que, se realmente fosse verdade, poderia ser explicada por algum problema no sangue e pela disposição do feto no útero materno no momento das trocas de alimentos. De fato, a umidade da região e o calor seriam responsáveis por essa assombrosa inversão de papéis, na qual o macho vinha provido de leite em suas mamas e ajudava na alimentação dos filhos. Somente numa terra de clima degenerado, segundo De Pauw, tal fato poderia ocorrer. ${ }^{20}$

Le Gentil de la Barbinais, em relatos de viagem da primeira metade do século XVIII, destacava que era impossível definir os povos oriundos do Brasil, especialmente os

\footnotetext{
19 IMLAY, Gilbert. Topographical description of the Western territory of North America: a succinct account of its soil, climate, Natural History, population, agriculture, manners and costums, with an ample description of the several divisions into which that Country is partitioned. London: Printed for J. Debrett, Third Edition, 1797. p. 226. Sobre a razão da coloração da pele dos nativos: "A judicious author of this country, who has written on the complexion and figure of the human species, has said 'a nation which migrates to a different climate will, in time, be impressed with the characters of its new state. The dark colour of the natives of the West India Islands is well known to approach very near to a dark copper. The descendents of the spaniards in South America are already become copper-coloured.' The Portuguese of Mitombo, in Sierra Leone, on the coast of Africa, have, by intermarriages with natives and by adpting their manners, become, in a few generations, perfectly assimilated in aspect, figure, and complexion. And Lord Kames, who can not be suspected of partiality on this subject, says of another portuguese settlement on the coast of Congo: 'that the descendants of those polished Europeans have become, both in their persons and in their manners, more like beasts than like men."

20 PAUW, Op. cit., p. 45.
} 
portugueses da terra, sendo, em primeiro lugar, enganoso considerá-los pela fisionomia e, principalmente, pela aparência de pessoas boas que demonstravam ser. Ele entendia que os luso-brasileiros eram dissimulados assim como os chineses e disfarçavam muito bem o ódio que nutriam pelos franceses, sobretudo por conta das guerras entre os locais e os oriundos de França que estiveram na costa do Brasil, no início daquela centúria. Dessa forma, as entidades governamentais existentes na Colônia sempre fingiam receber bem os estrangeiros, apresentando costumes civilizados à moda francesa, mas, simplesmente por desejarem auferir algum lucro ou algum benefício. E o comportamento característico dos americanos, daqueles aqui nascidos, contaminava os europeus que ficavam por algum tempo já que, segundo o viajante, "néamoins parmi ce grand nombre d’Escrocs, j'ai vû à la suíte du Viceroi plusieurs Officiers de Portugal qui remarquoient aussi bien que nous les vices de ces Americains, et qui pratiquoient avec plaisir les devoirs d'une honnête societé". ${ }^{21}$

Para Barbinais, os modos e a moral eram corrompidos no ambiente americano, os homens ostentavam uma postura indigna. As mulheres do Brasil eram, segundo o autor, desonradas, debochadas e viviam em evidente desordem pública. Os indivíduos que cuidavam da fé também não escapavam de sua escrita e eram caracterizados como ignorantes em matéria de sacerdócio, além de fazer pesar sobre eles a acusação de que mantinham relações com as ditas mulheres desonestas da terra. O viajante continuava suas observações a respeito dos nascidos na América e atentava para o fato de que as mulheres que eram mais virtuosas, aquelas cujas desordens comportamentais não iam a público, viviam trancafiadas em casa, rodeadas de um séquito de escravas que eram ornamentadas como se fossem damas, enfeitadas com pulseiras, anéis e braceletes de ouro, parecendo ser de uma camada social importante. Assim, as escravas, seus amantes brancos e as suas senhoras viviam em ambiente onde se compartilhavam não somente os benefícios de comércios ilegais, mas também a mesma cama.

Barbinais chocava-se ao perceber que os naturais do Brasil preferiam relacionar-se com uma mulher preta ou mulata do que com a mais bela mulher branca. E ao perguntar aos homens da terra de onde vinha tal gosto, nem eles mesmos sabiam explicar tal situação, entendida pelo viajante como bizarra. Então, o letrado encontrava uma explicação para esse comportamento desviante característico do homem americano e concluía que só podia estar no leite que as mulheres de cor passavam para as crianças quando da alimentação infantil. Assim, Barbinais completava sua exposição apontando os malefícios do leite daquelas escravas, algo que corrompia o bom sangue e transferia para o amamentado os mesmos vícios trazidos pelos negros em sua essência, ou seja, a vida sem moral e dissoluta. Por fim, relatava que teve a oportunidade de conhecer uma amável senhora de Lisboa casada com um homem do Brasil e que a discórdia causada por uma negra àquela relação fez com que o homem branco trocasse

21 BARBINAIS, Le Gentil de la. Nouveau voyage autour du Monde. Par monsier Le Gentil. Enrichi de plusieurs plans, vûës et perspectives des principales villes et ports du Pérou, Chily, Brésil et de la Chine, avec une description de l'Empire de la Chine, 1727. p. 201-202. 
a vida com sua mulher pelo amor de uma preta que não merecia a atenção nem mesmo do mais feio homem de toda a Guiné. ${ }^{22}$

Em relação à importância do leite no processo de degeneração dos rebentos, Jean Bernard Bossu, cinquenta anos após o relato de Barbinais, enfatizava que as damas brancas que eram conhecidas como crioulas, seguiram, na América espanhola, o uso das europeias de desdenhar o amamentar de seus filhos. Assim, entregavam sua prole a uma escrava negra, morena ou vermelha, sem pensar que o leite poderia corromper o sangue. Afinal, vários médicos competentes teriam demonstrado fisicamente que tal líquido afetava as inclinações latentes nos jovens. Com isso, o viajante declarava ter visto, muitas vezes, na América, vítimas inocentes da vida dissoluta de suas amas de leite, o que era algo fatal para a propagação do mal na espécie humana. ${ }^{23}$

Se, para Bossu, o leite das pretas corrompia o caráter humano, demonstrando falta de apreço para com as nações negras, por outro lado, ele buscava provar em toda sua obra que os ameríndios eram descendentes de antigos povos do Velho Mundo, destacando que a obra de Joseph-François Lafitau não deixara dúvida a respeito da origem dos nativos americanos. ${ }^{24}$ Porém, existia uma diferença entre Lafitau e Bossu: este último acreditava que o poder do clima era importante para a coloração da pele, embora não fosse o único fator que se deveria considerar. ${ }^{25}$

George Anson, na sua passagem pelo sul da América portuguesa, em meados do século XVIII, lembrava que havia muitos benefícios em se viver naquela região. No entanto, o clima poderia ser considerado como algo ruim que trazia malefícios para o corpo humano. Para o viajante "with regard to the climate, it must be remembered, that the woods and hills which surround the harbour, prevent a free circulation of the air". ${ }^{26} \mathrm{O}$ autor seguia explicando que a vegetação vigorosa existente naquela região era responsável pela formação de uma quantidade de vapor prodigiosa que, sobretudo à noite e na parte da manhã, causava um

22 BARBINAIS, ibid., p. 204.

23 BOSSU, Op. cit., p. 202.

24 BOSSU, Jean Bernard. Nouveaux voyages aux Indes Occidentales: contenant une relation des différens peuples quei habitent les environs du grand fleuve Saint-Louis appelé vulgairement le Mississipi. 2.ed. Paris: Le Jay Libraire, 1768. p. 188-189. O autor cita Lafitau: "La reflexion du Pere Laffiteau vous paroîtra juste. 'La description de ces Insulaires, dit-il, convient parfaitement aux Caraïbes, qui étoient maitres des Antilles, de la plus grande partie desquelles ils ont été chassés par les Européens, en ces derniers tems. La chair de ces Peuples est fort rougeatre: elle l'est naturellement; \& c'est moins un effet du climat, qui de l'imagination des meres, qui trouvent de la beauté dans cette couleur, la transmettent à leur fruit; elle I'est aussi par artifice; car les Barbares se sont peindre tous les jours avec le rocou qui leur tient lieu de vermillon, \& les fait paroître rouges comme du sang. Pour ce qui est de l'imagination de ces Matelots, qui croyoient voir des Satyres, elle ne venoit que de la peur qui leur faisoit prendre des queues postiches, pour des queues réelles. Presque toutes les Nations barbares de l'Amérique se donnent cet ornement, sur-tout quand elles vont en guerre'".

25 BOSSU, Op. cit., p. 189: "Les rapports qu'on trouve entre les usages de plusieurs Peuples de I'Amérique avec ceux de quelques Nations fort anciennes de notre continent, semblent démontrer que cette contrée n'a point été ignorée de l'antiquité; ils prouvent sur-tout que l'ancien Monde a fourni des hommes au nouveau; comment expliqueroient ils ces rapports si cela étoit arrivé autrement? Combien de ressemblance $n^{\prime} y$ a-t-il pas entre la religion, les moeurs, les coutumes des Sauvages \& celles de quelques Peuples anciens".

${ }^{26}$ ANSON, George. A voyage round the world in the years MDCC, XL, I, II, III, IV. Compiled from his papers and materials, by Richard Walter, M.A. Edinburgh: Printed by Campbell Denovan. Sold by the Booksellers, 1781. p. 49. 
nevoeiro espesso que fazia com que o local se tornasse mais úmido e, portanto, ocasionando mais doenças e interferindo nos humores humanos. Anson entendia que a humanidade presente nas terras portuguesas da América era degenerada do tronco principal. Indicando que o povo do Novo Mundo havia passado por um processo degenerativo, principalmente por conta do clima da região. Não há no viajante indícios de que tal processo fosse reversível. E nem vejo importância em buscar esse tipo de evidência, afinal de contas, o que está subjacente ao processo apresentado pelo autor é a posição inferior na qual ele alocava os nativos do Brasil, destacando, acima de tudo, o comportamento resultante do viver sob o ambiente avesso à vida, como ele entendia ser o caso da América.

A Expedição Malaspina pelos domínios da América espanhola, organizada sob os auspícios de Carlos III e Carlos IV no âmbito das chamadas reformas burbônicas, na segunda metade do século XVIII, confeccionou inúmeros diários que nos permitem entender um pouco sobre a forma como os participantes daquela empreitada classificavam a diversidade humana presente no Império espanhol. Por meio de seus relatos, Antonio Tova Arredondo nos revela a dificuldade que teve para entabular contato com os homens da região da Patagônia. Mas ressaltou que, após algumas conversas, foram bem recebidos por aqueles indígenas, sobretudo devido à presença do capitão da expedição, que já era conhecido dos nativos por ocasião de viagens anteriores. O viajante classificava os povos que encontrara somente pela perspectiva da análise dos caracteres físicos. ${ }^{27}$ Tova Arredondo questionava a tese do tamanho insignificante do homem americano; portanto, percebe-se que o autor conhecia as teorias buffonianas de que o nativo do Novo Mundo era mirrado e com proporções corporais débeis.

Chefe da expedição, Alejandro Malaspina também via atributos positivos nos nativos da região em apreço, embora considerasse que os índios Chonos fossem uns dos poucos infelizes que habitavam aquele território e que eram errantes, precisando se deslocar para conseguir alimentos, subsistindo contra todos os ditames da natureza, parecendo ao viajante que eram estranhos naquele solo e que haviam "realmente degenerado de los caracteres indicativos de la clase del hombre, pasando a una estupidez que no les es natural". ${ }^{28}$ Portanto, para Malaspina, os modos e costumes de determinadas tribos eram oriundos do processo de

27 ARREDONDO, Antonio Tova. Diário. In: La expedicion Malaspina (1789-1794). Madrid, Barcelona: Ministerio da Defesa, 1993. p. 77-82. Sobre algumas nações por ele analisadas, Arredondo destacava que: "Se midió la talla al cacique, resultando de seis pies dez pulgadas de Burgos, correspondiendo a la robustez de sus miembros y abultadas facciones, pero todos muy semejantes en lo fornidos, pudiendo asegurarse que aunque no deben pasar por gigantes, como quisieron suponer algunos viajeros, son generalmente de una talla y corpulencia muy superior a los europeos. Su color es semejante al cobre, la cabeza muy grande, igualmente que la cara y está algo achatada, frente llana y pequeña, ojos chicos y hundidos, nariz chata, boca grande, dientes pequeños, unidos y muy limpios, pelo negro, fuerte, y éste untado de una especie de aceite o grasa de lobo de malísimo odor; los hombres lo dejan suelto y lo contienen tan sólo con una cinta o correa que les ciñe la cabeza por la frente, y las mujeres, dividiéndole por mitad, formando coleta, que caen a uno y otro lado, por delante de los hombros, las cuelas adornan con cuentecitas de vidrio, cuando pueden adquirilas, lo mismo que el cuello y la muñeca, siendo este adorno más general en sus pequeños hijuelos. Entre éstos y las mujeres jóvenes se ven algunas caras no feas y de un color bastante claro, al paso que el de los adultos es oscurísimo, lo que prueba se éste efecto de la intemperie a que continuamente están expuestos".

28 MALASPINA, Alejandro. In: La expedicion Malaspina (1789-1794). Madrid, Barcelona: Ministerio da Defesa, 1993. p. 236. 
degeneração pelo qual passaram aqueles povos. Muito embora o autor não abordasse que tal processo fosse irreversível. ${ }^{29}$

Os diários pessoais que compõem os relatos da Expedição Malaspina nos fazem perceber que aquela equipe acreditava na influência do clima como promotora da diversidade humana; no entanto, não ressaltava que as características físicas, como a cor da pele, eram imutáveis. Contudo, subsidiados por academias de ciência e cientes das produções europeias feitas pelos naturalistas de gabinete que abordavam a natureza americana, esses viajantes da expedição, quase sempre, se deparavam com uma realidade diferente daquela que se encontrava nos compêndios filosóficos do Velho Mundo e, dessa forma, no contato e nas descrições dos nativos, apresentavam teses que contradiziam os corifeus das teorias sobre a diversidade humana na América.

La Pérouse, também no século XVIII, em sua longa viagem ao redor do mundo, ao contemplar diversos povos da América, observando-Ihes as características físicas e os modos, assim como faziam todos os viajantes em suas jornadas, afirmava que os escritores que defendiam a ideia de degeneração do homem americano estavam faltando com a verdade. Para La Pérouse não existia diferença substancial, como diziam os viajantes, entre a velocidade dos indígenas e a dos europeus, tampouco qualquer distinção entre os órgãos do sentido desses dois povos. E se realmente pudesse marcar uma grande diferença, seria a vantagem dos europeus serem civilizados. Assim, o curso da vida dos americanos parecia ter os mesmos períodos em relação ao aumento ou diminuição dos anos se comparado com o do europeus. Para o viajante, era preciso considerar que o clima, o estilo de vida e os hábitos conferiam algumas pequenas diferenças. Contudo, a defesa de que a América não era uma terra degenerada com seres humanos degradados não foi uma constante na obra de La Pérouse e seus colaboradores, mesmo o comandante da expedição, diferentemente do que ele afirmava no volume quarto de sua vasta obra, no segundo volume, ele apontava para povos do Novo Mundo que eram degenerados. ${ }^{30}$

\footnotetext{
29 MALASPINA, Op. cit., p. 238. Sobre os nativos do Chile, ele destacava que "La población de Chiloé se compone en el día de 27,000 almas, los 15,300 españoles, los 11,700 indios, depende esencialmente esta diferencia de los fueros que se han conocido a los unos y negado a los otros; [y] entrando por consiguiente en la classe de los primeros cualesquiera nuevos colonos que la suerte deparase a estas regiones. Los indios son conocidamente huilliches y dotados por consiguinte de las dos caracteristicas de aquella nación: desconfianza y superstición, degenerando ésta en una excessiva crueldad en los prestigios y encantos que transciende no sólo a las enfermedades, partos, etc., si también al uso del veneno, como sea autorizado de las señales augurales y la necesidad de liberarse de un enemigo, de una mujer, de un marido. No difieren de ellos en esta parte de los mismos criollos o españoles, en los cuales la ninguna educación, ni roce con las demás colonias, y el natural apego y promiscuación con las mujeres, depositarias por lo común de esta especie de costumbres, ha hecho que muy luego más bien se asemejan a los [españoles] habitadores antiguos de la isla, más bien que introducir las que debían heredar de sus padres".

30 LA PÉROUSE, Jean-François de. Voyage de La Pérouse autour du Monde (v. 2). Paris: De l'imprimerie de la République, 1797. p. 64. Sobre determinadas nações: "Le peuple de la Conception est très-voleur, et les femmes y sont extrêmement complaisantes: c'est une race dégénérée, mêlée d'Indiens; mais les habitant du premier état, les vrais Espagnols, sont extrêmement polis et obligeans. Je manquerais à toute reconnaissance, si je les peignais avec les vraies couleurs qui conviennent à leur caractère; je tâcherai de le faire connaître en racontant notre propre histoire".
} 
Na viagem de La Pérouse, os nativos do Chile não foram abordados como pertencentes a uma casta de degenerados, como bem aparece em um dos diários apresentados por José de Moraleda na Expedição Malaspina. Portanto, era comum que viajantes distintos, que passavam por locais e povos diferentes, possuíssem opiniões contraditórias a respeito de uma mesma nação. M. Rollin, doutor em medicina, ao tecer suas memórias sobre fisiologia e patologia, durante a estadia de La Pérouse no Chile, destacava os aspectos que particularizavam os índios daquela região. ${ }^{31} \mathrm{E}$ ao comparar as duas anotacões a respeito dos nativos do Chile, percebe-se que os autores franceses, como o médico da viagem de La Pérouse, mantinham a regularidade de considerar a estatura e a robustez dos ameríndios, como fator de inferioridade se comparados com os europeus, especialmente o homem francês. Tais apreciações inexistem nos relatos dos espanhóis da Expedição Malaspina. De todo modo, é possível encontrá-las nos relatos do século XVII, em autores da América espanhola. Ou seja, o tamanho diminuto dos homens e dos animais do Novo Mundo visto como uma das marcas da degeneração causada, quase sempre, pelo clima do continente recentemente descoberto e então explorado.

No século XVIII, Saint-Méry, nascido em terras americanas, destacava que as três classes de humanos que compunham a população de Santo Domingo eram distintas fisicamente, levando aquela população a ser bem diferente das que constituíam a Europa. Na verdade, segundo o autor, seria um grande erro conceder a cada uma dessas três classes um caráter próprio, muito embora cada uma delas tivesse suas particularidades, que pareciam formar subdivisões. ${ }^{32}$ Assim, existiam diversas causas que justificavam as diferenças entre os nativos americanos e os europeus, mas, "particulièrement l'action d'un soleil constamment brûlant, produisent dans les habitants de la zone torride des modifications qui les diffèrer des habitants de zones tempérées". ${ }^{33}$

Desse modo, os americanos nascidos em Santo Domingo eram chamados de crioulos e, geralmente, eram homens bem-feitos e com bom tamanho, possuíam uma figura corporal bastante regular, muito embora fossem privados da cor branca que a natureza realçava na pele dos indivíduos dos países frios; os olhos dos crioulos eram expressivos e, como estavam livres do aperto das roupas, os membros dos corpos raramente ofereciam alguma

\footnotetext{
31 LA PÉROUSE, ibid., p. 36-37: "La structure du corps, chez ces Américains, n'offre rien de particulier: leur stature est en général moins grande que celle des Français, et ils paraissent aussi beaucoup moins robustes; cependant ils supportent avec beaucoup de courage les fatigues de la guerre, et toutes les privations qu'elle traîne à sa suite. [...] Le même caractère de physionomie se fait remarquer chez presque tous les individus de cette nation: leur visage est large et plus arrondi que celui des Européens; ils ont les traits grossiers, les yeux petits, ternes, noirs et enfoncés, le front bas, les pommettes saillantes, les lévres épaisses, la bouche grande, le menton peu prononcé, et les oreilles de forme ordinaire. [...] La couleur de leur peau est d'un brun rougeâtre, et celle des ongles, un peu moins foncée. Ils ont également les cheveux noirs, très-forts et très-épais. Les hommes ont peu de barbe, mais leurs aisseles et leurs parties naturelles sont assez bien garnies de poils: presque toutes les femmes en sont dépourvues à ces parties".

32 SAINT-MÉRY, Médéric Louis Élie Moreau de. Description topographique, physique, civile, politique et historique de la partie française de l'ile Saint-Domingue avec des observations générales sur sa population sur le caractère et les moeurs de șes divers habitants, sur son climat sa culture, ses productions, son adminitrastion, etc... Deuxième Édition, Paris: Edite par L. Guerin Et Cie, Tome Premier, 1875. p. 7.

33 SAINT-MÉRY, id., p. 13.
} 
deformidade. Além disso, para o autor, a temperatura do clima conferia aos nativos uma agilidade adequada aos exercícios físicos, pelos quais eles teriam um carinho especial.

No tocante às nações negras, o autor entendia que esses povos estavam menos sujeitos à influência do clima quando de seu traslado para a América; era como se eles se sentissem em casa. Cuidavam somente para que tivessem itens de primeira necessidade, limitados, sem preocupações, principalmente com o futuro. E dessa disposição de alma, segundo o autor, vinha a indolência, estado de espírito favorito dos negros. Eram homens privados de qualquer educação, entregues a todos os preconceitos, a todos os terrores da ignorância, fracos e medrosos em relação aos desafios que poderiam encontrar pela frente.

Quanto às características dos corpos, Saint-Méry afirmava que entre os negros tais atributos variavam muito, pois eram oriundos de diversas partes da África. Assim, para perceber o que havia de uno ou plural entre aqueles homens, era melhor observá-los de acordo com suas origens. Mas, de uma forma geral, ao se tornarem moradores de Santo Domingo, esses africanos também se transformavam em seres indolentes, preguiçosos, briguentos, mentirosos e viciados em roubo, independentemente da região de origem. Assim, "I'influence de leurs moeurs primitives et la disproportion même du nombre des femmes, comparé à celui des hommes, dont les premières ne forment guères qu'une moitié, sont des causes très-naturalles de cette pluralité que le climat favorise encore". ${ }^{34} \mathrm{Em}$ Saint-Méry, o contato do africano com as terras americanas proporcionava o aumento e a disseminação de traços negativos que eram inerentes aos povos oriundos da África.

Para o autor, as crianças filhas de pais negros possuíam uma cor indecifrável ao nascer, em que se podia observar um tom avermelhado que mudaria com o correr dos dias, muito embora se percebesse de antemão algumas manchas escuras nas unhas, o que demonstrava que aquele rebento seria negro. Por outro lado, ao longo da vida, algumas moléstias poderiam modificar a cor da pele dos indivíduos negros, entre elas a varíola, que conferia pontos mais escuros na pele, ou qualquer outra doença que causasse a palidez. Além disso, ele entendia que o tom preto da pele dos negros era a razão pela qual não se notava com clareza a idade das pessoas, principalmente dos mais velhos, ainda mais que nos homens quase não se percebia a barba, e a brancura só aparecia nos cabelos depois de muitos anos.

Saint-Méry também via com curiosidade os homens de cor preta que se descoloriam ao longo da vida ou nasciam com formatos da raça negra, mas com a pele branca. Eram os albinos ou negros brancos, como eram chamados nas colônias. Dessa forma, ele apresentava alguns exemplos, como uma negra mãe de sete ou oito crianças que, no município de Maribaroux, teve o primeiro e o último filho albinos, todos originários do mesmo pai. Também teve contato com um prisioneiro chamado John White, em 1783, em St. Louis, preso por não se reapresentar à milícia, um negro livre que era albino, apesar de seus oitos irmãos serem escravos e negros, e esse soldado era casado com uma mulher negra que lhe dera cinco filhos,

34 SAINT-MÉRY, ibid., p. 41-44. 
todos de cor preta, além de uma negra, na Martinica, que teve gêmeos e um filho nascera preto e o outro albino.

Pierre-Louis Moreau de Maupertuis, em 1745, abordava o albinismo. Ele pretendia explicar a razão de filhos de pretos nascerem com a pele branca, mas, acima de tudo, tencionava entender outros muitos fenômenos mais difíceis e mais importantes com relação às diferentes espécies de homens que se encontravam sobre a Terra. Ele concluía que o clima era responsável pela cor preta dos indivíduos da zona tórrida, que o ambiente temperado era responsável pela beleza dos povos que habitavam naquelas terras, ao passo que as regiões glaciais eram responsáveis por produzir seres disformes. Com isso, arrematava que essa pluralidade de espécies poderia ser explicada por algo que se encontrava nos corpos dos seres humanos, desde sua concepção.

Ainda em Saint-Méry, vemos que os negros eram povos degenerados que não sabiam contar, não conseguiam diferenciar tamanhos e pesos, nem indicar diferentes moedas. Não sabiam a própria idade, não se lembravam quando eram perguntados a respeito de tempos passados. Eram gentes que surpreendiam negativamente os brancos com suas escritas e comunicações de ideias, com palavras em suas línguas que lembravam a invocação de demônios, inclusive sendo o Diabo uma das explicações para a origem daquelas nações. 0 autor lembrava que muitos negros diziam que Deus teria feito o homem e o teria feito branco; o Diabo, com ciúmes, fez um ser parecido com a criatura feita pelo Criador, mas Deus acabou escurecendo o homem feito pelo demônio para que sua obra perfeita não fosse confundida com a arranjada pelo espírito maligno. Satã, tão irritado com a tintura dada por Deus à cópia, teria ficado nervoso, desferindo um tapa na cara da sua obra e, assim, achatou-Ihe o nariz e fez inchar os lábios. ${ }^{35}$

Quanto à cor da pele, o capitão Gilbert Imlay também entendia que o clima interferia nas particularidades dos corpos, mas descartava a hipótese de que degenerava os seres, considerando, inclusive, que apontar para a baixa intelectualidade dos negros, colocando-os em patamar de bárbaros, era uma irresponsabilidade quando se estava comparando nações reduzidas à escravidão, sem instruções e sem liberdade, com povos como os europeus, livres na sua razão e aptos para o desenvolvimento, exatamente por exercerem sua liberdade.

Para Edward Long, advogado inglês que migrou para a Jamaica em 1760, a primeira e mais importante indicação de que os americanos pretos diferiam dos brancos era a cor preta da pele, uma vez que existia naqueles corpos uma membrana escura que se comunicava com a pele dos seres oriundos da África. E tal membrana, assim como a cor da pele dos africanos, não mudava, mesmo que os negros fossem transportados a um clima diferente. Assim, eles nunca perdiam aquela gradação preta, exceto em caso de doenças como a lepra ou acidentes que os levavam a ter queimaduras. Long afirmava que eram de outra raça de homens. Para o autor, uma das características marcantes era o cabelo dos africanos, que lembrava uma lã bestial, uma espécie de pelo que mais parecia de animais. O arredondamento dos olhos, os

35 SAINT-MÉRY, ibid., p. 75. 
narizes achatados, lábios grossos invariáveis e também a grande dimensão dos mamilos femininos, como se tivessem sido adaptados pela natureza para o tamanho das bocas das crianças, também eram marcas que se sobressaíam. Outro detalhe que chamava a atenção de Long era a cor preta dos piolhos que infestavam os corpos dos negros. Uma circunstância tão peculiar aos olhos do autor, que ele lamentava que nenhum naturalista tivesse percebido isso antes. Por fim, de acordo com Long, os piolhos dos negros se assemelhavam aos dos homens brancos na forma, mas eram maiores e mais escuros.

Em Long, outro enfoque concedido ao homem preto era o seu cheiro fétido e bestial, o que todos possuíam em maior ou menor grau, especialmente os de Angola que eram, segundo o autor, os mais estúpidos da raça dos negros, os mais ofensivos; os de Senegal, que se distinguiam por serem de um rebanho com mais compreensão e mais brandura, também eram os que possuíam menor potencial para aquele odor nocivo. Esse cheiro forte, nos dizeres de Long, exalado especialmente quando os corpos eram aquecidos pelo exercício da raiva, continuava nos lugares por mais de um quarto de hora, mesmo quando os negros já não estavam mais presentes.

A questão do odor era tão discutida que, para Bossu, os crocodilos americanos encontrados à beira do Mississipi eram animais sedentos por carne humana e eles atacavam principalmente os negros, por conta de um forte cheiro que exalava de sua pele, quando eles transpiravam. O autor defendia a degeneração daquela espécie de homens, em particular por causa da exposição ao inóspito clima africano. Por fim, apontava que o ambiente americano piorou a situação, concluindo com base na consideração dos atributos externos e também internos dos africanos e seus filhos nascidos na América, que eram gente de uma raça distinta da europeia. ${ }^{36}$

Ainda segundo Long, os negros e seus descendentes que se tornaram americanos, em termos de faculdades mentais, permaneciam no mesmo modo grosseiro e estúpido; ou seja, a situação em que se encontravam havia mais de dois mil anos antes da sua escrita ser publicada. Em geral, o autor os descrevia como mulas e quase incapazes de qualquer progresso na civilidade ou na ciência. Nos seus dizeres, não existia nenhum plano ou sistema de moralidade em meio àquela raça. Gente sem sensações morais, sem gosto para mulheres, dada aos vícios e à bebedeira em geral, sendo seus filhos criaturas sofridas desde os mais tenros anos e se entregando a tudo que a natureza Ihes oferecia. Não nutriam nenhum prazer pelas partes mais bonitas do seu país; ao contrário, preferiam as partes estéreis. Eram, enfim, "represented by all authors as the vilest of the human kind, to which they have little more pretension of resemblance than what arises from their exterior form". ${ }^{37}$

\footnotetext{
36 BOSSU, Jean Bernard. Nouveaux voyages aux Indes Occidentales: contenant une relation des différens peuples quei habitent les environs du grand fleuve Saint-Louis appelé vulgairement le Mississipi. 2.ed. Paris: Le Jay Libraire, 1768. p. 87.

37 LONG, Edward. The history of Jamaica: or, general survey of the antient and modern state of the island: with reflections on its situation settlements, inhabitants, climate, commerce, laws, and government. London: Printed for T. Lowndes, 1774. p. 352.
} 
Edward Long duvidava ser prudente colocar os negros oriundos da África e mesmo os nascidos na América no mesmo patamar de espécie humana em que se encontravam os brancos; o autor entendia que a influência do clima teria sua importância, sobretudo nos humores dos indivíduos, mas concluía que a mudança de clima não era suficiente para transformar as características dos seres humanos. E apontava que, assim como existiam diferentes classes de animais, também era plausível que se encontrassem distintas raças humanas. ${ }^{38}$

Saint-Mèry, a partir da Martinica, por volta de 1780, abraçava a ideia de que era impossível reverter a degeneração ocorrida entre os grupos humanos. Defendia que era preciso considerar as duas cores principais como constituintes de todos os outros seres, ou seja, o branco e o preto. E, para o autor, o preconceito colonial teria ajudado a disseminar a ideia de que da união entre um homem branco e uma mulher de cor só resultaria em um ser de cor; da mesma forma que da união entre um negro e uma mulata sempre resultaria em um indivíduo que não era um preto original. Em outras palavras, somente no encontro sexual entre brancos é que teríamos criaturas brancas, dando-se o mesmo com os negros. Com isso, o autor negava a possibilidade de retorno à cor original, caso indivíduos mantivessem relações com outros distintos de suas cores de pele.

Mas, considerando as misturas de todas as combinações de branco e preto, o mulato era o que reunia as maiores vantagens físicas; ou seja, "de tous ces croisements de races", ${ }^{39}$ dizia o autor, era o povo que possuía a mais forte constituição, a mais adequada ao clima da América, principalmente no ambiente de Santo Domingo. Assim, "a la sobriété et à la force du nègre, il unit la grâce dans les formes et I'inteligence du blanc". ${ }^{40}$ No fim, os mulatos chegavam até a idade avançada sem ter cabelos ou peles deformadas, sempre sem pelos nos corpos, assim como os negros, com os cabelos também lembrando os pelos de animais, no entanto mais longos do que os de seus ancestrais africanos.

De acordo com Saint-Méry, as mulheres mulatas gostavam de esbanjar elegância e gastavam quase todo o dinheiro com enfeites e os tipos mais caros de linho. Eram poucas que se casavam com homens da sua própria raça e, quando isso acontecia, era um tipo de união que se demonstrava defeituosa e estéril. Long também afirmava, com base nos estudos que fez sobre a obra de Buffon, nunca ter visto um casal de mulatos dar à luz filhos que chegassem à puberdade; para ele, a união desses dois indivíduos de mesma raça não redundava em geração porque eles eram como as mulas: estéreis. Ao contrário, se uma mulata tivesse relações com homens pretos ou brancos, decerto, teria vasta prole. E se, durante suas observações, viu alguma mulher mulata ter filhos que sobreviveram, estando casada com outro mulato, certamente seria um filho de alguma relação extraconjugal, pois entendia que a lascívia e a mentira estavam bem próximas desses indivíduos da raça mulata. ${ }^{41}$

\footnotetext{
38 LONG, ibid., p. 353-354.

39 SAINT-MÉRY, ibid., p. 87.

40 SAINT-MÉRY, ibid., p. 87.

41 LONG, ibid., p. 335-336.
} 
Ao fim e ao cabo, ele concluía que "for my own part, I think there are extremely potent reasons for believing, that the White and the Negroe are two distinct species". ${ }^{42}$ A posição do viajante inglês contraria, por exemplo, a tese da historiadora Roxann Wheeler que defende que a cor da pele e os caracteres físicos dos indivíduos não eram importantes para os ingleses, no século XVIII, ao se compararem com as demais nações existentes na Terra. ${ }^{43}$

\section{Conclusão}

Como se observa nos relatos de viagens e nas obras teóricas apresentadas acima, existia um número considerável de variantes que entravam no processo de explicação das razões da diversidade humana encontrada na América. Mas, ainda assim, a coloração da pele e os caracteres físicos eram o principal ponto a ser considerado na construção dos inventários do homem do Novo Mundo. E para a maior parte das descrições aqui apresentadas, a humanidade americana estava alocada em chave classificatória distinta daquela em que se encontrava o europeu, ou seja, eram humanos degenerados. Portanto, no século XVIII, a forma de se vestir, a prática do comércio, a religião enfim, poderiam contar no processo de avaliação da América; mas os traços mais evidentes que marcavam as diferenças eram os estampados na pele e nos corpos dos povos daquelas terras.

As viagens promovidas pelos impérios europeus aos seus domínios no Novo Mundo ao mesmo tempo que apresentaram a diversidade natural existente naquelas paragens também apontaram as características de uma humanidade que nasceu sob o signo da miscigenação e, portanto, ia em direção oposta àquela considerada ideal, a branca europeia. Os súditos dos grandes impérios europeus na América, não aceitando o lugar em que foram colocados na classificação da humanidade, responderam com dados científicos e procuraram de alguma maneira justificar a mistura entre brancos e indígenas e, quase sempre, condenar a miscigenação com os negros. Desses embates, se solidificava no Século das "Luzes" a ideia de raça no seu entroncamento com os caracteres físicos, por conseguinte, o racismo com base científica, muito embora, circunscrito àquela conjuntura, não guardasse as características do racismo biologizante que se desenvolveria na centúria seguinte.

Por fim, entendo que os inventários do homem americano produzidos na América, fosse por nativos ou pelos europeus nas suas andanças pelas terras novas, foram de uma riqueza tão extraordinária que possibilitaram aos centros de pesquisas e aos teóricos da diversidade humana, amparados pelos seus gabinetes de estudos no Velho Mundo, proporem distintas teses que pudessem dar conta da diversidade presente no Novo Mundo. Mas essas hipóteses também se mostravam ineficientes quando confrontadas com a realidade encontrada por novos indivíduos que passavam à América. O real contato com o novo continente, quase

\footnotetext{
42 LONG, ibid., p. 336.

43 WHEELER, Roxann. The complexion of race: categories of difference in eighteenth-century British culture. Philadelphia: University of Pennsylvania Press, 2000
} 
sempre, demonstrava algo muito mais complexo do que as informações apresentadas pelos teóricos.

E essas teorias eram relidas, reinterpretadas e se lançavam novos olhares sobre o assunto, inclusive a visão dos nativos da América que, antenados com as hipóteses em voga na Europa, também se punham a escrever sobre a humanidade aqui encontrada. $O$ confronto entre essas informações fez nascer o homem americano. Nos trópicos, a humanidade que se desenvolveu não só chocava por se afastar dos desígnios cristãos, mas também assustava pela sua cor de pele, seus cabelos e os formatos dos seus corpos. A ideia de raça que já apostava na separação, na classificação religiosa ou nobre, caiu como que perfeita para se referir à separação por conta das diferenças físicas.

Bruno Silva: Possui graduação em História pela UFF. Mestre em História pela mesma universidade, com o tema "Negros, Índios e Mestiços nas Crônicas de Pernambuco e São Paulo Setecentistas", abordando tópicos como "Identidades Coloniais". Doutor em História Social pela UFF, com a tese Inventários do Homem Americano: viagens, teorias e composição das Raças nos Séculos XVII e XVIII, sob orientação do Professor Ronald José Raminelli e com estágio doutoral na Universidade do Texas. 